\title{
Selective Metabolite and Peptide Capture/Mass Detection using Fluorous Affinity Tags
}

\author{
Eden P. Go ${ }^{1}$, Wilasinee Uritboonthai ${ }^{1}$, Junefredo V. Apon ${ }^{1}$, Sunia A. Trauger ${ }^{1}$, Anders \\ Nordstrom ${ }^{1}$, Grace O'Maille ${ }^{1}$, Scott M. Brittain ${ }^{2}$, Eric C. Peters ${ }^{2,{ }^{\star}}$, and Gary Siuzdak ${ }^{1,{ }^{\star}}$ \\ 1 Department of Molecular Biology and The Center for Mass Spectrometry, The Scripps Research Institute, \\ 10550 North Torrey Pines Road, La Jolla, CA 92037
}

2The Genomics Institute of the Novartis Research Foundation, 10675 John Jay Hopkins Drive, San Diego, CA 92121

\section{Abstract}

\begin{abstract}
A new and general methodology is described for the targeted enrichment and subsequent direct mass spectrometric characterization of sample subsets bearing various chemical functionalities from highly complex mixtures of biological origin. Specifically, sample components containing a chemical moiety of interest are first selectively labeled with perfluoroalkyl groups, and the entire sample is then applied to a perfluoroalkyl-silylated porous silicon ( $\mathrm{pSi}$ ) surface. Due to the unique hydrophobic and lipophobic nature of the perfluorinated tags, unlabeled sample components are readily removed using simple surface washes, and the enriched sample fraction can then directly be analyzed by desorption/ionization on silicon mass spectrometry (DIOS-MS). Importantly, this fluorous-based enrichment methodology provides a single platform that is equally applicable to both peptide as well as small molecule focused applications. The utility of this technique is demonstrated by the enrichment and mass spectrometric analysis of both various peptide subsets from protein digests as well as amino acids from serum.
\end{abstract}

\section{Keywords}

affinity; fluorous; mass spectrometry; metabolites; porous silicon

\section{Introduction}

Affinity based fractionation schemes are often applied to complex protein samples before mass spectrometric characterization in order to focus the analysis on a particular subset of analytes of interest. These methodologies rely on highly selective chemical or biological affinities exhibited by various classes of capture reagents such as biotin-strepavidin, lectins, aptamers, immobilized chelated metals etc. ${ }^{1-5}$ Typically, samples are first incubated with the appropriate affinity ligand immobilized onto a solid support. This support is then extensively washed to remove non-binding entities as well as other sample contaminants. Finally, the analytes of interest are eluted from the affinity resin and characterized by MS. By comparison, direct mass spectrometric characterization of enriched analytes still bound to the affinity capture reagent should provide more rapid and sensitive analyses of targeted analytes. There have been numerous reports in the literature describing the use of various laser desorption/ionization techniques to analyze species directly from the surface of affinity reagents. ${ }^{6-13}$ Here, we 
describe a new variation of such an affinity/enrichment approach based on the unique interplay between fluorous-tagged analytes and a fluorous-silylated DIOS surface.

Since the introduction of fluorous biphasic catalysis techniques, ${ }^{14}$ the field of fluorous chemistry has expanded rapidly. ${ }^{15}$ The term "fluorous" was coined to represent highly fluorinated (or perfluorinated) species in a way analogous to how "aqueous" represents waterbased systems. Fluorous molecules are solvophobic, in that they prefer to reside in a fluorous environment rather than an organic or aqueous phase. Fluorous solid phase extraction (FSPE) takes advantage of this unique property to easily separate fluorous-labeled species from nonlabeled species utilizing fluorous-functionalized media. ${ }^{16}$ Traditionally, this technology has been used for the targeted synthesis and subsequent purification of small molecules, ${ }^{17,18}$ peptides ${ }^{19}$ and oliogonucleotides. ${ }^{20}$ However, the utility of fluorous-based methodologies has recently been extended to more biochemical focused applications such as proteomics 21,22 and microarray construction. 23

Recently, the development of silylated DIOS surfaces has been reported. ${ }^{24}$ The chemical functionality of such surfaces can readily be manipulated by employing simple silylation reactions on an ozone-oxidized porous silicon (pSi) interface. Because of this flexibility, it allows chemical interactions of high selectivity to be used for affinity/enrichment and/or purification methods on silylated DIOS surfaces that enable on-plate sample clean up and subsequent analyses with improved sensitivity and reproducibility. Herein, we describe the use of perfluoroalkyl-silylated DIOS targets as affinity surfaces that enable the direct enrichment and subsequent mass spectrometric analysis of targeted analyte subsets from complex mixtures. Importantly, the same fluorous derivatization and enrichment methodology can readily be applied for the selective fractionation and direct analysis of both peptidic as well as small molecule-containing samples. We also demonstrate for the first time the potential advantages of pre-analysis fractionation of metabolomic samples by functional class in the analysis of amino acids in serum samples.

\section{Experimental Section}

\section{Materials}

All reagents were obtained in high purity from Sigma-Aldrich (St Louis, MO) or Fisher Scientific (Fairlawn, NJ) except when noted otherwise. Ammonium bicarbonate $\left(\mathrm{NH}_{4} \mathrm{HCO}_{3}\right)$, trifluoroacetic acid (TFA), glucose, bovine serum albumin (BSA), bovine $\alpha-$ casein, iodoacetamide (IAA), dithiothreitol (DTT), barium hydroxide $\left(\mathrm{Ba}(\mathrm{OH})_{2}\right)$, tris (2carboxyethyl)phosphine hydrochloride (TCEP.HCl), sodium triacetoxyborohydride (NaBH $(\mathrm{OAc})_{3}$ ), tetrahydrofuran (THF), urea, dimethyl sulfoxide (DMSO), phenylalanine and tyrosine were obtained from Sigma (St. Louis, MO). Hydrofluoric acid (HF), glacial acetic acid, Optima-grade acetonitrile $\left(\mathrm{CH}_{3} \mathrm{CN}\right)$ and Optima-grade methanol were obtained from Fisher Scientific. Sequencing grade modified trypsin (Tp) was obtained from Promega (Madison, WI). Leptin peptide fragment (116-130) amide (mouse) was from Bachem (Torrance, CA). $N-(1 \mathrm{H}, 1 \mathrm{H}, 2 \mathrm{H}, 2 \mathrm{H}$-perfluorooctyl)iodoacetamide, $N-(1 \mathrm{H}, 1 \mathrm{H}, 2 \mathrm{H}, 2 \mathrm{H}-$ perfluordecyl)iodoacetamide, 3-(perfluorooctyl)propylamine, 3-(perfluorobutyl)propan-1-ol, 3-(perfluorohexyl)propan-1-ol and 1H,1H,2H,2H-perfluorooctyl-1-thiol were purchased from Fluorous Technologies, Inc. (Pittsburgh, PA). (Heptadecafluoro-1,1,2,2-tetrahydrododecyl) dimethylchlorosilane and (tridecafluoro-1,1,2,2-tetrahydrooctyl)trichlorosilane were obtained from Gelest, Inc. (Morrisville, PA). Water was purified by a Barnstead Nanopure system (Dubuque, IA). Stock solutions for all small molecules were prepared by reconstituting a lyophilized sample in milli-Q water at $1 \mathrm{mg} / \mathrm{mL}$ and performing additional serial dilutions as needed. 


\section{Derivatization of Small Molecules}

A volume of $100 \mu \mathrm{L}$ was aliquoted from a stock solution of the appropriate small molecule (amino acids and simple carbohydrates) into a $2 \mathrm{~mL}$ glass capped vial and slowly evaporated to dryness. Amino acids were derivatized to their esters by dissolving the dried aliquot in 150 $\mu \mathrm{L}$ of the appropriate alcohol and $50 \mu \mathrm{L}$ of concentrated $\mathrm{HCl}$ and incubating the mixture at $65^{\circ}$ $\mathrm{C}$ for 1 hour. Excess reagent was removed by evaporating the reaction mixture to dryness. The derivatized samples were reconstituted with $50 \% \mathrm{MeOH} / \mathrm{H}_{2} \mathrm{O}$ and a series of working solutions were prepared in water. Simple carbohydrates were derivatized by reductive amination using perfluorinated amine and $\mathrm{NaBH}(\mathrm{OAc})_{3}$ as the reducing reagent. ${ }^{25}$ Briefly, dried carbohydrates (30 nmol) were dissolved in $8 \mu \mathrm{L}$ anhydrous DMSO containing $3 \mu \mathrm{L}$ of $0.3 \mathrm{M}$ perfluorinated amine and $1 \mu \mathrm{L}$ acetic acid. Five microliters of $6.2 \mathrm{M} \mathrm{NaBH}(\mathrm{OAc})_{3}$ was added, and the mixture was incubated at $65^{\circ} \mathrm{C}$ for 1.5 hours. The derivatized sample was applied to a strip of Whatmann $3 \mathrm{MM}$ chromatography paper (Fisher Scientific) and allowed to dry. The paper was placed in a chromatography tank containing $\mathrm{CH}_{3} \mathrm{CN}$ and the solvent was allowed to rise to the top of the paper. The spot at the origin was cut out and extracted with $150 \mu \mathrm{L}$ of $50 \% \mathrm{MeOH} / \mathrm{H}_{2} \mathrm{O}$, and a series of working solutions were prepared in water.

\section{Fluorous Chromatographic Separation of Esterified Amino Acid}

Fluorous chromatography 18 was performed with an Agilent 1100 series fitted with capillary pump heads on a $150 \mathrm{~mm} \times 4.6 \mathrm{~mm}$ FluoroFlash ${ }^{\circledR}$ HPLC column (Fluorous Technologies Incorporated) at a flow rate of $1 \mathrm{~mL} /$ minute. Gradient separation included a linear gradient of $85-100 \%$ B over 10 minutes was used to elute the esterified phenylalanine. Mobile phase A was $50 \mathrm{mM}$ ammonium acetate and mobile phase B was $0.1 \%$ formic acid in $\mathrm{MeOH}$.

\section{Preparation of the Amino Acid Extract from Serum Samples}

Cold methanol (100 $\mu \mathrm{L}$ ) was added to human serum (male, H-1388; Sigma-Aldrich) samples $(50 \mu \mathrm{L})$ and the mixture was vortexed for $1 \mathrm{~min}$. Samples were placed for $20 \mathrm{~min}$ in a $4^{\circ} \mathrm{C}$ block to aid protein precipitation and then centrifuged at $13,400 \times \mathrm{g}$ for $10 \mathrm{~min}$ at $4^{\circ} \mathrm{C}$ to pellet the protein. The supernatant was transferred into a clean $2 \mathrm{~mL}$ glass vial and derivatized using the amino acid reaction protocol described previously. The derivatized extracts were reconstituted with water.

\section{Fluorous Derivatization of Cysteinyl Residues}

$20 \mu \mathrm{L}$ of a $5 \mu \mathrm{M}$ solution of leptin peptide fragment (116-130) amide (mouse) in $0.1 \mathrm{M}$ $\mathrm{NH}_{4}(\mathrm{HCO})_{3}(\mathrm{pH} 8.0)$ was mixed with $5 \mu \mathrm{L} 1 \mathrm{M} \mathrm{NH}_{4}(\mathrm{HCO})_{3}, 20 \mu \mathrm{L}$ THF and alkylated with $5 \mu \mathrm{L}$ of a $500 \mathrm{mM}$ stock solution in THF of $N-(1 \mathrm{H}, 1 \mathrm{H}, 2 \mathrm{H}, 2 \mathrm{H}$-perfluordecyl)iodoacetamide. The reaction was allowed to react for 30 minutes at $37^{\circ} \mathrm{C}$ in the dark, and $450 \mu \mathrm{L}$ of cation exchange loading buffer (20 mM ammonium formate, $\mathrm{pH} 3.0$ in $60 \%$ (v/v) MeOH) was added. The reaction mixture was loaded onto an Opti-Lynx trap cartridge $(100 \mu \mathrm{L}, 4.6 \times 5 \mathrm{~mm})$ packed with $40 \mu \mathrm{m}$ strong cation exchange particle (Optimize Technologies, Oregon City, OR) and washed with $2 \times 500 \mu \mathrm{L}$ aliquots of cation exchange loading buffer. The fluorous labeled peptide was eluted with $500 \mu \mathrm{L}$ of $20 \mathrm{mM}$ ammonium formate $\mathrm{pH} 3.0$ in $95 \%$ (v/v) $\mathrm{MeOH}$ in water, and a series of working solution were prepared in water.

BSA was dissolved in $100 \mu \mathrm{L}$ of $4 \mathrm{M}$ urea in $0.1 \mathrm{M} \mathrm{NH}_{4}(\mathrm{HCO})_{3}(\mathrm{pH} 8.0)$ and reduced with $10 \mathrm{mM}$ TCEP at room temperature for 10 minutes. The reduced BSA solution $(5 \mu \mathrm{M}, 20 \mu \mathrm{L})$ was mixed with $5 \mu \mathrm{L} 1 \mathrm{M} \mathrm{NH}_{4}(\mathrm{HCO})_{3}, 20 \mu \mathrm{L}$ THF and alkylated with $5 \mu \mathrm{L}$ of a $500 \mathrm{mM}$ stock solution in THF of $N-(1 \mathrm{H}, 1 \mathrm{H}, 2 \mathrm{H}, 2 \mathrm{H}$-perfluorooctyl)iodoacetamide. The reaction was allowed to react for 30 minutes at $37^{\circ} \mathrm{C}$ in the dark, and the reaction mixture was diluted directly into SDS-PAGE loading buffer. 


\section{Fluorous Derivatization of Phosphoserine/Phosphothreonine Residues}

$\alpha$-casein $(10 \mu \mathrm{M}, 5 \mu \mathrm{L})$ were combined with an equal volume of 3:1 DMSO/ethanol (v/v), followed by the addition of $4.6 \mu \mathrm{L}$ saturated $\mathrm{Ba}(\mathrm{OH})_{2}$ and $1 \mu \mathrm{L} 500 \mathrm{mM} \mathrm{NaOH}$. Finally, 0.7 $\mu \mathrm{L}$ of $1 \mathrm{H}, 1 \mathrm{H}, 2 \mathrm{H}, 2 \mathrm{H}$-perfluorooctane-1-thiol was added and the solution allowed to react at 37 ${ }^{\circ} \mathrm{C}$ for $1 \mathrm{~h}$. The reaction was stopped by the addition of $5 \mu \mathrm{L} 5 \%$ TFA (v/v), and the reaction mixture was diluted directly into SDS-PAGE loading buffer.

\section{Processing and In-Gel Digestion of Labeled Proteins}

SDS-PAGE was performed using $1 \mathrm{~mm}$ thickness 10-20\% Tris-Glycine polyacrylamide minigels (Invitrogen, Carlsbad, CA), loaded with 50-100 pmol of derivatized protein. Molecular weight marker standard was run in both flanking lanes. The gel slab was then stained with colloidal Coomassie blue (Invitrogen, Carlsbad, CA) for 4 hours, followed by destaining in water overnight. Excised protein gel bands were first cut into small cubes $(2-3 \mathrm{~mm})$ with a sterile razor blade and added to $0.5 \mathrm{~mL}$ microcentrifuge tubes. The gel cubes were subjected to a repeated wash and dehydrate cycle involving addition of $50 \mu \mathrm{L} 100 \mathrm{mM}$ ammonium bicarbonate for $10 \mathrm{~min}$, removal, then $25 \mu \mathrm{L}$ acetonitrile for 10 minutes and removal. Next, the dehydrated gel cubes were vacuum dried for 5 minutes. Finally, the gel cubes were rehydrated in $20 \mu \mathrm{L} 50 \mathrm{mM}$ ammonium bicarbonate solution containing $10 \mathrm{ng} / \mu \mathrm{L}$ trypsin (Promega, Madison, WI) and incubated at $37^{\circ} \mathrm{C}$ overnight. Tryptic peptides were recovered by repeated extraction (3X) with $80 \%$ acetonitrile/0.2\% TFA (v/v). The peptide extracts were combined then dried in vacuo. The samples were then reconstituted in $60 \%$ methanol containing $10 \mathrm{mM}$ ammonium formate as preparation for fluorous surface enrichment experiments.

\section{DIOS Chip Preparation}

The details of DIOS chip preparation have been described elsewhere. ${ }^{26,27}$ Briefly, DIOS chips were prepared by etching low resistivity $(0.005-0.02 \Omega$-cm) n-type $\mathrm{Si}(100)$ wafers (Silicon Quest International, Santa Clara CA) in 25\% v/v hydrofluoric acid/ethanol under white light illumination at a current density of $5 \mathrm{~mA} / \mathrm{cm}^{2}$ for 2 minutes. Photopatterning was performed to create 100 sample spots on each chip. Immediately after etching, the DIOS chip was rinsed with ethanol and dried under a stream of $\mathrm{N}_{2}$ to give an $\mathrm{H}$-terminated surface, then oxidized by direct exposure to ozone (flow rate of $0.5 \mathrm{~g} / \mathrm{h}$ ) from an ozone generator (Epotech, Houston, TX) directed at the surface for 30 seconds. After ozone oxidation, the DIOS chip surface was placed in a Petri dish and covered with $100 \mu \mathrm{L}$ of silylating reagent for fluorous modification.

\section{Chemical Modification of pSi Surfaces}

Surface derivatization involved the modification of hydroxyl groups present on the ozoneoxidized porous silicon surface by silylation with either (tridecafluoro-1,1,2,2-tetrahydrooctyl) trichlorosilane or (heptadecafluoro-1,1,2,2-tetrahydrododecyl)dimethylchlorosilane. ${ }^{24}$ These reactions generate perfluoroalkyl-derivatized DIOS surfaces. Each silylation reaction was performed by adding $15 \mu \mathrm{L}$ of the appropriate silylating reagent onto the surface of the oxidized DIOS chip, placing the chip in a glass Petri dish and incubating it in an oven at $65^{\circ} \mathrm{C}$ for 15 minutes. The modified DIOS chip was then rinsed thoroughly with methanol and dried under a stream of $\mathrm{N}_{2}$.

\section{Mass Spectrometry}

DIOS-MS experiments were conducted on an Applied Biosystems Voyager STR mass spectrometer operated in the positive ion mode. This instrument was equipped with automated and multisampling capabilities for rapid sample analysis. DIOS chips were attached to a modified MALDI target plate with conductive tape. After any on-chip washing protocols, samples were desorbed from the surface by irradiation with a $337 \mathrm{~nm} \mathrm{~N}_{2}$ laser operated at 5 
Hz. The accelerating voltage was set to $20 \mathrm{kV}$ and the delayed extraction time to $150 \mathrm{~ns}$ to obtain optimized mass resolution. Mass spectra were generated by averaging at least 100 individual laser shots into a single spectrum.

Electrospray ionization (ESI) tandem MS analysis of fluorous derivatized species were performed on a Micromass Q-ToF micro system equipped with a Z-spray electrospray source and a lockmass sprayer in the positive ion mode. Samples were introduced by direct infusion using an integrated syringe pump at a flow rate of $5 \mu \mathrm{L} / \mathrm{min}$. The source temperature was set to $110^{\circ} \mathrm{C}$ with a cone gas flow of $50 \mathrm{~L} / \mathrm{h}$, a desolvation gas temperature of $365^{\circ} \mathrm{C}$ and a nebulization gas flow of $350 \mathrm{~L} / \mathrm{h}$. The capillary voltage was set at $2.8 \mathrm{kV}$ and the cone voltage at $25 \mathrm{~V}$. The collision energy was set at $16 \mathrm{~V}$.

\section{Safety Considerations}

Extreme care should be taken in handling hydrofluoric acid solutions because of their toxicity and corrosiveness. All inhalation, ingestion, or skin and eye contact should be strictly avoided. Etching of silicon wafers should be conducted in a ventilated fume hood using proper doublelayered nitrile gloves, lab coat, and face shield. Hydrofluoric acid solution spills and burns can be neutralized and treated with $2.5 \%$ calcium gluconate gel.

\section{Results and Discussion}

To date, fluorous methodologies have overwhelmingly been employed as processing aides for the targeted synthesis and purification of specific small molecules. Accordingly, we reasoned that such samples would enable an effective initial evaluation of the feasibility of using fluorous-silylated DIOS targets to directly affect both the enrichment and subsequent MS analysis of fluorous labeled species. Figure 1a provides a schematic representation of such an on-target fluorous enrichment and analysis experiment. All components of a sample bearing a chemical functionality of interest are first selectively labeled with perfluoroalkyl groups using a chemoselective reaction as shown in Scheme 1. After removal of excess reagent, the entire sample is transferred to a fluorous-silylated DIOS target, and if desired, analyzed in its entirety by DIOS-MS. The resulting sample area is then repeatedly washed with a solution containing a significantly high percentage of organic solvent (i.e. $50 \% \mathrm{MeOH}$ ). These washes remove the majority of species bound to the surface primarily by hydrophobic interactions, thus enriching the fluorous labeled species on the analysis target and enabling their subsequent focused analysis.

Figure $1 \mathrm{~b}$ shows the DIOS-MS analyses of the crude reaction products of either the reductive amination of glucose using a $\mathrm{C}_{8} \mathrm{~F}_{17}$-functionalized amine (left) or the esterification of tyrosine with a $\mathrm{C}_{6} \mathrm{~F}_{13}$-functionalized alcohol (right). The deposited samples ( $\sim 100 \mathrm{pmol}$ and $10 \mathrm{fmol}$ of fluorous tagged glucose and tyrosine, respectively) were then repeatedly washed with $50 \%$ $\mathrm{MeOH}$ in water, and the DIOS-MS analyses were repeated. Clearly, this washing procedure removed many of the impurities observed in the mass spectrum of the crude reductive amination reaction mixture, thus affecting a dramatic enrichment of the fluorinated analyte. By contrast, the esterification reaction contained few background peaks that stayed after washing. Significantly though, the fluorous reaction product was fully retained on the DIOS target despite the application of numerous high organic content washes.

Solutions containing such high percentages of organic solvent are known to disrupt hydrophobic interactions between most small molecule analytes and C18 columns in reversedphase high performance liquid chromatography (RP-HPLC). However, in order to unequivocally demonstrate the unique enrichment opportunities provided by this fluorous methodology, we needed to preclude the possibility that the observed phenomenon originated primarily as a result of the significant hydrophobicity of perfluoroalkyl chains. To this end, we 
examined the effect of increasing methanol percentage in the wash solution on the noncovalent binding interaction between a fluorous affinity capture surface and phenylalanine esterified with either 3-(perfluorobutyl)propan-1-ol or 1-heptanol. Multiple identical samples of each ester were deposited and dried on individual analysis sites on a fluorous silylated DIOS target and subsequently washed with solutions of differing percentages of methanol in water. Each sample was then analyzed by DIOS-MS, and the average signal intensities from triplicate measurements were plotted as a function of the percentage of $\mathrm{MeOH}$ in the wash solution. As shown in Figure 2a, an increase in the level of organic solvent is required to remove the fluorous ester from the surface of the DIOS target, despite the fact that both alcohols used for the esterification possess identical carbon chain lengths. Additionally, the retentions of two fluorous and two non-fluorous esterified compounds on a fluorous chromatography column bearing a $\mathrm{Si}\left(\mathrm{CH}_{2}\right)_{2} \mathrm{C}_{8} \mathrm{~F}_{17}$ bonded phase were measured using an increasing gradient of methanol in $50 \mathrm{mM}$ ammonium acetate. As seen in Figure 2b, the fluorous esters were highly retained on the column, with the longer fluorous chain derivative being more tightly bound. In contrast, the non-fluorous compounds eluted early from the column with little distinction between derivatives of different alkyl chain length. Taken together, these results demonstrate that the unique selectivity observed is clearly not primarily a function of increased

hydrophobicity but rather reflects a unique interplay between fluorous-tagged analytes and the fluorous-modified target surface.

Having demonstrated the feasibility of this fluorous-based methodology to enable the selective enrichment and subsequent direct DIOS-MS analysis of small molecules, we decided to explore whether the same platform could also be employed for the enrichment and analysis of peptide subsets. Given the fact that the appended fluorous affinity tags utilized would constitute a significantly smaller relative percentage of the mass of a labeled peptide compared to that of a typical small molecule, it was decided to first test the feasibility of this methodology using labeled peptide standards. Thus, the cysteine residue of the $20 \mu \mathrm{M}$ leptin peptide fragment (116-130) amide was reacted with the fluorous alkylating reagent $N-(1 \mathrm{H}, 1 \mathrm{H}, 2 \mathrm{H}, 2 \mathrm{H}-$ perfluordecyl)iodoacetamide and purified as described. A solution containing a 5:1 mixture (v/v) of $20 \mu \mathrm{M}$ each of the unmodified and fluorous-labeled peptide was deposited on a fluorous-silylated DIOS target, air dried and analyzed. As shown in Figure 3a, peaks for both the unmodified and labeled peptides were observed at their expected $\mathrm{m} / \mathrm{z}$ values of 1561 and 2079 respectively (see inset), as well as a peak at a $\mathrm{m} / \mathrm{z}$ value of 3120 corresponding to the dimer of the untagged leptin peptide formed by covalent disulfide linkage in solution. By contrast, after washing the same sample location with $60 \% \mathrm{MeOH}$ in water and repeating the DIOS-MS analysis, only signals for the labeled peptide and its potassium salt were observed.

The same labeled peptide standard was also spiked into a $200 \mathrm{fmol}$ tryptic digest of BSA in order to test the effectiveness of the enrichment methodology in the presence of numerous other peptides spanning a broader range of hydrophobicity. This mixture was deposited onto the fluorous-silylated DIOS surface, air dried and analyzed. As shown in Figure 3b, numerous peaks corresponding to predicted BSA tryptic peptides were observed in addition to the fluorous labeled species. By contrast, analysis of the same location after washing with $60 \%$ $\mathrm{MeOH}$ in water showed a dramatic reduction in the signals of the various assigned BSA tryptic peptides with a concomitant enhancement in sensitivity of at least 20 -fold for the fluorous labeled peptide and its potassium salt.

Having demonstrated the effective surface enrichments obtainable using fluorous affinity tags and fluorous-silylated DIOS surfaces, we next sought to demonstrate that the required labeling reactions could effectively be performed on protein samples. Thus, reduced BSA, which contains 35 cysteine residues, was alkylated at the protein level by reacting its cysteine residues with $N-(1 \mathrm{H}, 1 \mathrm{H}, 2 \mathrm{H}, 2 \mathrm{H}$-perfluorooctyl)iodoacetamide. The labeled protein was then subjected to all the operations typical of gel-based proteomics (i.e. SDS-PAGE, in gel tryptic digestion 
and extraction of all resulting peptides from the gel whether labeled or not), and the extracted peptides were deposited on a fluorous-silylated DIOS target, air dried and analyzed. Figure 4a shows the DIOS-MS spectra of the spotted sample. LC-MS/MS experiments of the same sample allowed for the observation of 19 fluorous labeled peptides (allowing for a single miscleavage) which were identified from MS/MS database search using Mascot (Supplementary Figure 1 online). However, unlike in LC/MS/MS analysis where peptides are separated in time and analyzed, fewer peptides were observed due to signal suppression that occurs when all peptides are present simultaneously in a DIOS-MS analysis. In addition, the presence of chemical reagents for tagging and fluorous-by-products also contributed to signal suppression. As a result, only two fluorous peptides and 5 unlabeled peptides were observed on the unwashed sample (Figure 4a). Despite this, the resulting DIOS mass spectrum exhibits strong signals corresponding to expected masses of both native as well as fluorous labeled tryptic BSA peptides as seen in Figure 4a. By contrast, washing the deposited sample with $50 \% \mathrm{MeOH}$ in water and subsequent DIOS analysis yielded a spectrum exhibiting signals corresponding to the fluorous labeled peptides. In addition, another species at $\mathrm{m} / \mathrm{z} 534$ was retained after on-surface washing indicating that this species is a reaction by-product.

Similarly, Figure $4 \mathrm{~b}$ demonstrates the selective enrichment and analysis of phosphopeptides using a different chemical derivatization scheme. Intact $\alpha$-casein was subjected to $\beta$-elimination under basic conditions followed by Michael addition of $1 \mathrm{H}, 1 \mathrm{H}, 2 \mathrm{H}, 2 \mathrm{H}$-perfluorooctane-1-thiol, and the resulting modified protein was processed as described previously. The extracted peptides were deposited on a fluorous-silylated DIOS target, air dried and analyzed. As seen in Figure $4 \mathrm{~b}$, the resulting DIOS mass spectrum exhibits numerous strong signals corresponding to expected $\alpha$-casein tryptic peptides, but no signals corresponding to the derivatized phosphopeptides are observed. By contrast, washing the deposited sample with $60 \% \mathrm{MeOH}$ in water and subsequent DIOS analysis yielded a spectrum in which the two most intense peaks correspond to the $\mathrm{C}_{6} \mathrm{~F}_{13}$-labeled $\alpha$-casein phosphopeptides, VPQLEIVPNsAEER and YKVPQLEIVPNsAEER $(\mathrm{m} / \mathrm{z}$ values of 1943 and 2235, respectively). The identities of these two peptides were confirmed in a separate LC-MS/MS experiment (data not shown). Combined, these two examples demonstrate that the described fluorous labeling and enrichment techniques are completely compatible with SDS-PAGE processing. More importantly, this surface enrichment methodology enables the facile analysis of both the full initial sample (i.e. protein identification) as well as a targeted subset (i.e. identification of post-translational modifications) from the same target location simply by employing a facile surface washing procedure.

Based on these results, we decided to investigate whether this highly facile fluorous-mediated fractionation of samples into subsets bearing specific chemical functionalities would similarly benefit metabolomics analyses. It is well known that the identification and characterization of metabolites in complex biological matrices such as serum is hindered by the presence of proteins, inorganic salts and endogenous background compounds. ${ }^{28,29}$ These species cause signal suppression and thus should be removed in order to improve the sensitivity and the reliability of the analysis. Proteins are typically removed by precipitation in organic solvents ${ }^{30}$ while inorganic salts are separated from the majority of endogenous organic compounds by solid phase extraction procedures. However, the subsequent analysis of species of interest is typically performed in the presence of all other endogenous metabolites. Thus, we reasoned we would be able to improve the analyses of specific species by first affecting their enrichment employing fluorous analogs of classic metabolite derivatization chemistries.

An enrichment scheme targeting metabolites bearing carboxylic acid moieties was investigated, as this functionality is a common chemical motif present in endogenous metabolites and is amenable to tandem MS analysis after esterification. Indeed, esterification is a commonly used derivatization scheme in neonatal screening, as it facilitates amino acid 
analysis by increasing the ionization efficiencies of these compounds. 31 Thus, endogenous metabolites were extracted from serum using cold methanol, and after drying, were esterified with either 3-(perfluorobutyl)propan-1-ol or the typically employed 1-butanol for comparison. These derivatizations result in a mass shift of $260 \mathrm{Da}$ for the fluorous alcohol or $56 \mathrm{Da}$ for butyl alcohol per carboxylic acid moiety reacted. The derivatized extracts were reconstituted in water and deposited onto a fluorous-silylated DIOS surface using DIOS solid-liquid extraction. $^{24}$

As shown in Figure 5, the DIOS spectrum of the sample derivatized with the fluorous alcohol exhibits significantly improved signals for the esterified amino acids of phenylalanine, proline, glutamic acid, aspartic acid and leucine/isoleucine compared to the sample derivatized with 1butanol. Additionally, signals for the esterified amino acids of tyrosine and valine are only observed in the spectrum of the fluorous-derivatized sample. The assignment of these species was confirmed by both DIOS post source decay (PSD) as well as ESI-MS/MS analyses (Supplementary Figures 2, 3, and 4 online). Presumably, this improved sensitivity results from the selective enrichment of the fluorous-derivatized species away from other endogenous background metabolites not containing a carboxylic acid moiety. This supposition is bolstered by the fact that PSD and ESI-MS/MS analyses of other prominent signals in the fluorousderivatized sample show the same characteristic neutral loss of $306 \mathrm{Da}$ exhibited by the esterified amino acids (see Figure 5a inset), indicating that these species also contain carboxylic acid functionalities. A rapid desorption ionization technique such as DIOS-MS for the analysis of amino acids in human serum could potentially be very powerful since many inherited metabolic disorders such as phenylketonuria (PKU) can routinely and accurately be diagnosed by monitoring the concentration ratio of certain amino acids in extracts of neonatal blood specimens. $28,32,33$

\section{Conclusions}

Fluorous affinity methodologies afford a straightforward and facile method for purification and enrichment of samples prior to mass spectral analysis. Specifically, the unique interplay between fluorous-derivatized species and the surface of a perfluoroalkyl-silylated DIOS target enables the direct enrichment and subsequent mass spectrometric analysis of targeted analyte subsets from complex mixtures. Importantly, the same fluorous derivatization and enrichment methodology can readily be applied for the selective fractionation and direct analysis of both peptide as well as small molecule based samples. Accordingly, this methodology has been utilized to show for the first time the benefits of fractionation of small molecule samples by functionality before mass spectral analysis.

\section{Supplementary Material}

Refer to Web version on PubMed Central for supplementary material.

\section{Acknowledgements}

This work was supported by NIH SNAPS grant MH062261 and DOE grant DE-AC02-05CH11231. A.N. is supported by a postdoctoral fellowship from The Swedish Research Council (VR).

\section{References}

1. Ficarro SB, McCleland ML, Stukenberg PT, Burke DJ, Ross MM, Shabanowitz J, Hunt DF, White FM. Nat Biotechnol 2002;20(3):301-305. [PubMed: 11875433]

2. Gygi SP, Rist B, Gerber SA, Turecek F, Gelb MH, Aebersold R. Nature Biotechnol 1999;17(10):994999. [PubMed: 10504701]

3. McLachlin DT, Chait BT. Anal Chem 2003;75(24):6826-6836. [PubMed: 14670042] 
4. Nilsson CL. Anal Chem 2003;75(15):348A-353A.

5. Shen M, Guo L, Wallace A, Fitzner J, Eisenman J, Jacobson E, Johnson RS. Mol Cell Proteomics 2003;2(5):315-324. [PubMed: 12766232]

6. Dick LW Jr, McGown LB. Anal Chem 2004;76(11):3037-3041. [PubMed: 15167780]

7. Lin YS, Tsai PJ, Weng MF, Chen YC. Anal Chem 2005;77(6):1753-1760. [PubMed: 15762582]

8. Meng JC, Siuzdak G, Finn MG. Chem Commun (Camb) 2004;(18):2108-2109. [PubMed: 15367998]

9. Neubert H, Jacoby ES, Bansal SS, Iles RK, Cowan DA, Kicman AT. Anal Chem 2002;74(15):36773683. [PubMed: 12175153]

10. Petricoin EF, Liotta LA. Curr Opin Biotechnol 2004;15(1):24-30. [PubMed: 15102462]

11. Raska CS, Parker CE, Dominski Z, Marzluff WF, Glish GL, Pope RM, Borchers CH. Anal Chem 2002;74(14):3429-3433. [PubMed: 12139050]

12. Tang N, Tornatore P, Weinberger SR. Mass Spectrom Rev 2004;23(1):34-44. [PubMed: 14625891]

13. Wang H, Tseng K, Lebrilla CB. Anal Chem 1999;71(10):2014-2020. [PubMed: 10361500]

14. Horvath IT, Rabai J. Science 1994;266(5182):72-75. [PubMed: 17814001]

15. Luo ZY, Zhang QS, Oderaotoshi Y, Curran DP. Science 2001;291(5509):1766-1769. [PubMed: 11230688]

16. Curran DP. Synlett 2001;(9):1488-1496.

17. Zhang W. Cur Op Drug Discov Devel 2004;7(6):784-797.

18. Zhang W. Chem Rev 2004;104(5):2531-2556. [PubMed: 15137799]

19. de Visser PC, van Helden M, Filippov DV, van der Marel GA, Drijfhout JW, van Boom JH, Noort D, Overkleeft HS. Tetrahedron Lett 2003;44(50):9013-9016.

20. Miura T, Goto KT, Hosaka D, Inazu T. Angew Chem -Intl Ed 2003;42(18):2047-2051.

21. Brittain SM, Ficarro SB, Brock A, Peters EC. Nat Biotechnol 2005;23(4):463-468. [PubMed: 15768030]

22. Brittain, SM.; Peters, EC.; Brock, A. Proceedings of the 53rd ASMS Conference on Mass Spectrometry and Allied Topics; San Antonio, Texas. June 5-9, 2005; TP0163

23. Ko KS, Jaipuri FA, Pohl NL. J Am Chem Soc 2005;127(38):13162-13163. [PubMed: 16173741]

24. Trauger SA, Go EP, Shen Z, Apon JV, Compton BJ, Bouvier ES, Finn MG, Siuzdak G. Anal Chem 2004;76(15):4484-4489. [PubMed: 15283591]

25. Dalpathado DS, Jiang H, Kater MA, Desaire H. Anal Bioanal Chem 2005;381(6):1130-1137. [PubMed: 15761738]

26. Shen ZX, Thomas JJ, Averbuj C, Broo KM, Engelhard M, Crowell JE, Finn MG, Siuzdak G. Anal Chem 2001;73(3):612-619. [PubMed: 11217770]

27. Wei J, Buriak JM, Siuzdak G. Nature 1999;399(6733):243-246. [PubMed: 10353246]

28. Chace DH. Chem Rev 2001;101(2):445-477. [PubMed: 11712254]

29. Villas-Boas SG, Mas S, Akesson M, Smedsgaard J, Nielsen J. Mass Spectrom Rev 2005;24(5):613646. [PubMed: 15389842]

30. Want EJ, O'Maille G, Smith CA, Brandon TR, Uritboonthai W, Qin C, Trauger SA, Siuzdak G. Anal Chem 2006;78(3):743-752. [PubMed: 16448047]

31. Millington DS, Kodo N, Terada N, Roe D, Chace DH. Intl J Mass Spectrom Ion Processes 1991;111:211-228.

32. Chace DH, Sherwin JE, Hillman SL, Lorey F, Cunningham GC. Clin Chem 1998;44(12):2405-2409. [PubMed: 9836704]

33. Chace DH, Kalas TA, Naylor EW. Annu Rev Genomics Hum Genet 2002;3:17-45. [PubMed: 12142359] 


\section{a. Fluorous Affinity/Enrichment Approach}

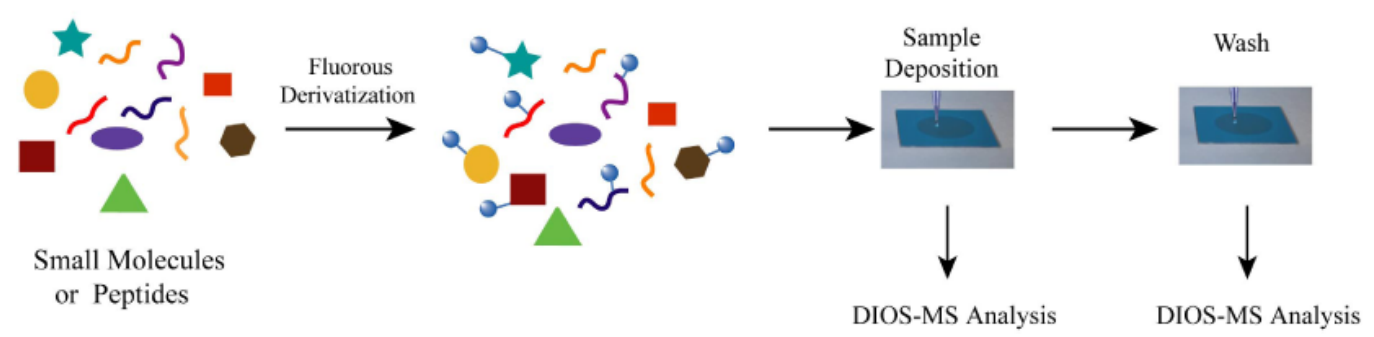

\section{b. Affinity Enrichment of Fluorous Tagged Small Molecules}
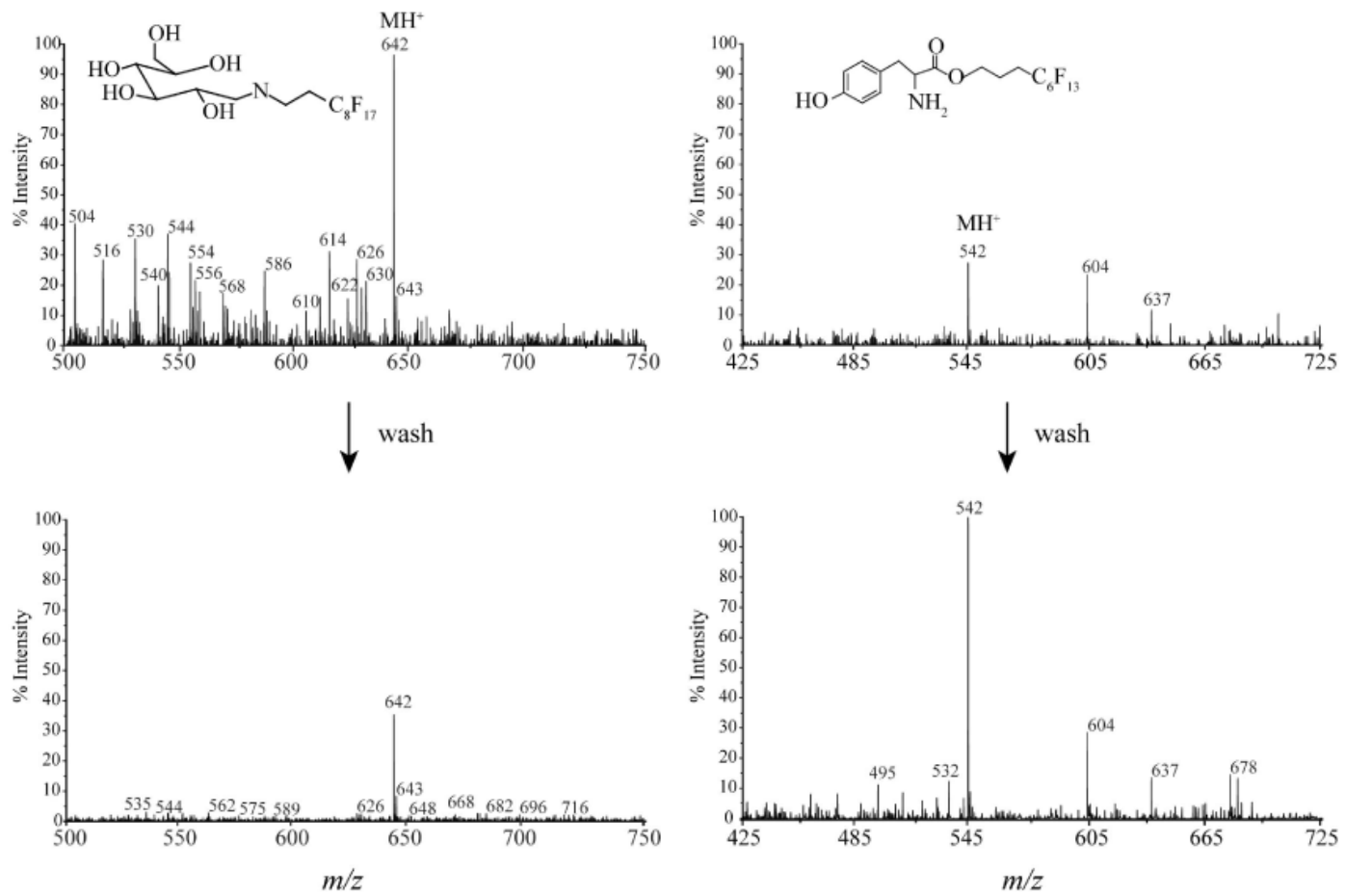

Figure 1.

a) Schematic representation of the fluorous affinity/enrichment approach. b) DIOS-MS spectra of 100 pmol fluorous tagged glucose and $10 \mathrm{fmol}$ fluorous tagged tyrosine before and after the samples were washed on the fluorous-silylated DIOS surface with $50 \% \mathrm{MeOH}$ in water. 
a. Binding Affinity of Esterified Amino Acid

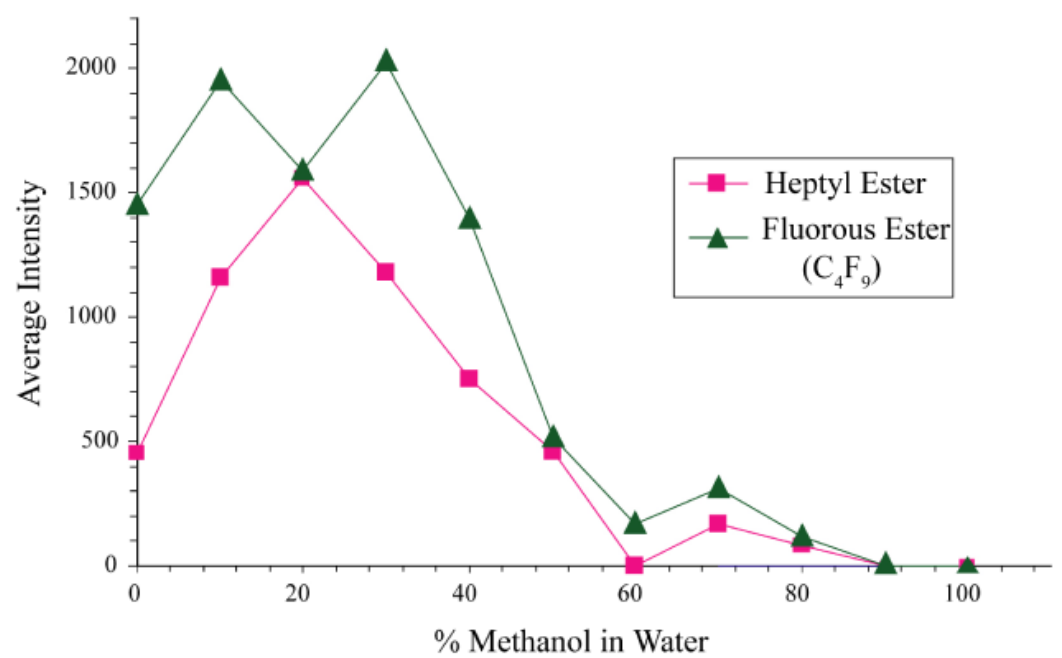

b. Total Ion Chromatogram of the Esterified Amino Acid

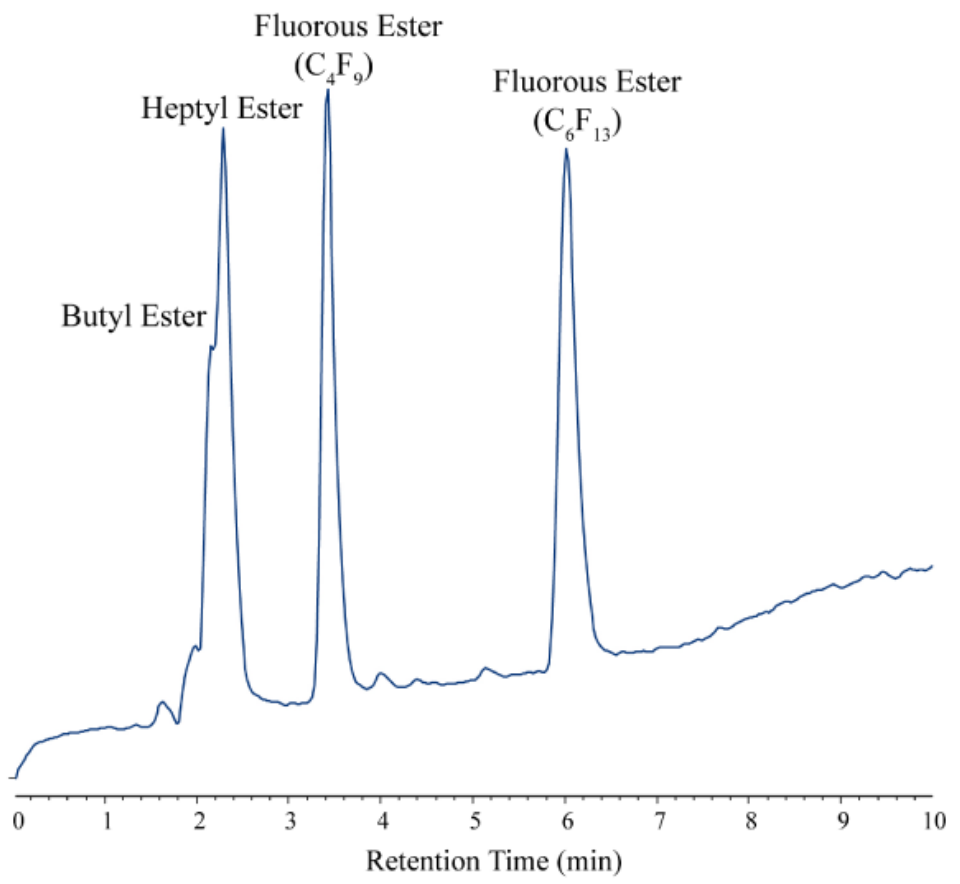

Figure 2.

a) Changes in intensity of DIOS-MS signals for 3-(perfluorobutyl)propyl and heptyl ester derivatives of phenylalanine after direct washing with varying percentages of methanol in water on a perfluoroalkyl-silylated DIOS target. b) Retention times of four ester derivatives of phenylalanine on a FluoroFlash ${ }^{\circledR}$ HPLC column using an increasing gradient of methanol in $50 \mathrm{mM}$ ammonium acetate. 
a. Mixture of Leptin and Fluorous Tagged Leptin
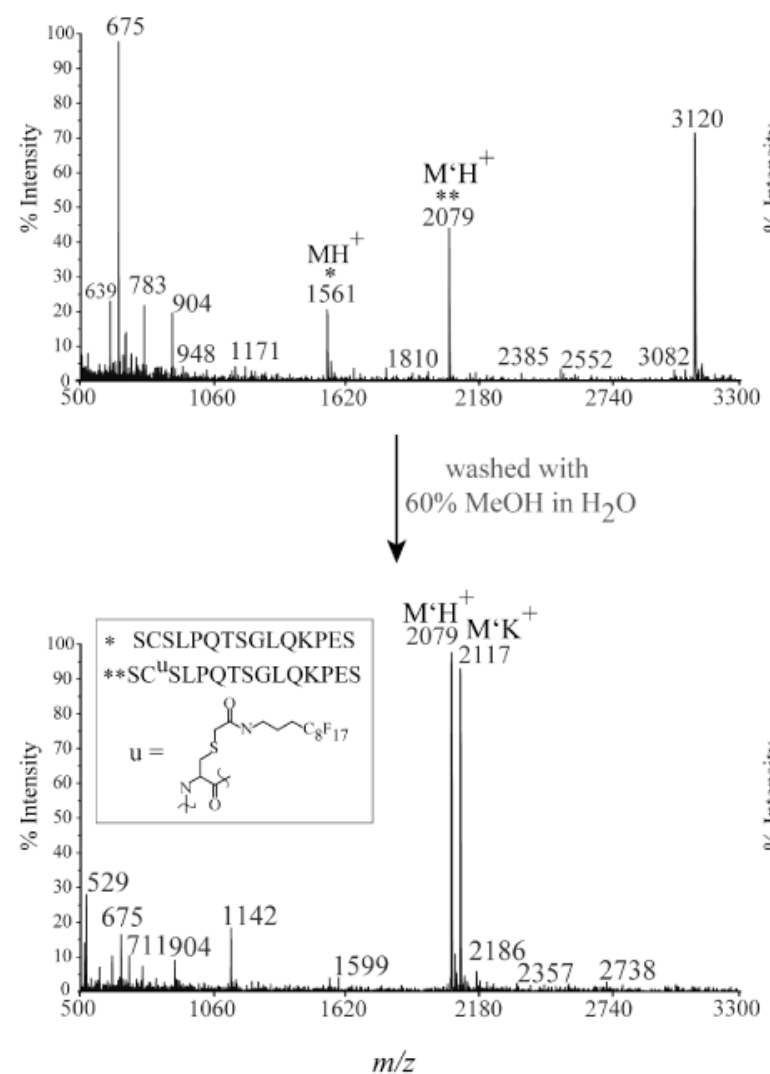

b. BSA Digest spiked with Flourous Tagged Leptin

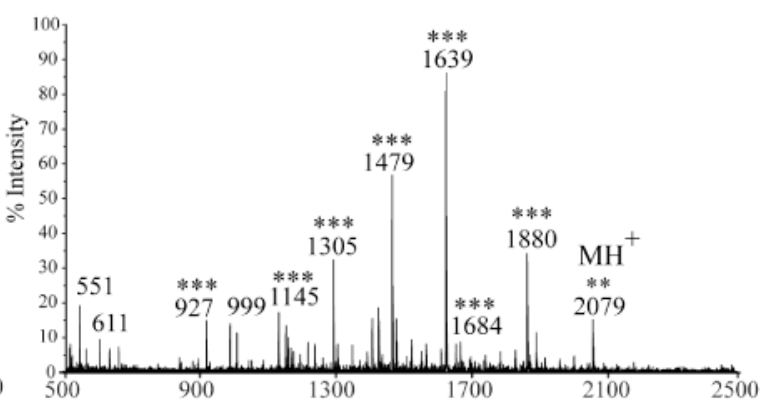

washed with $60 \% \mathrm{MeOH}$ in $\mathrm{H}_{2} \mathrm{O}$

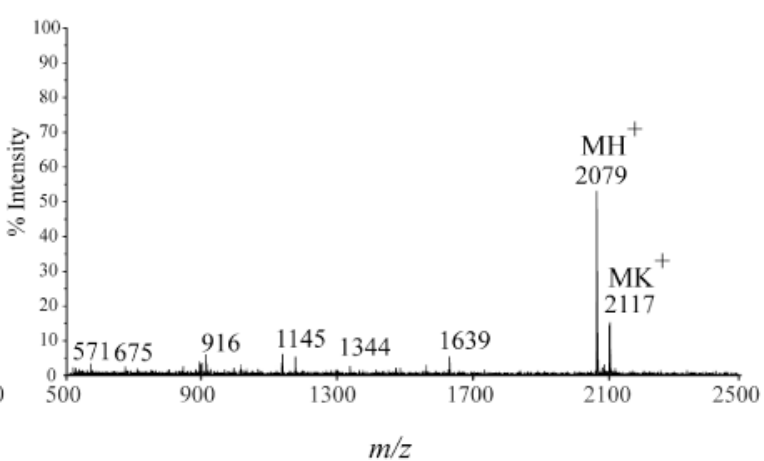

Figure 3.

DIOS-MS spectra before and after employing a surface washing step of a) a mixture of $8 \mathrm{pmol}$ native and 2 pmol fluorous tagged peptide standard, and b) $200 \mathrm{fmol}$ BSA digest spiked with 2 pmol of same fluorous tagged peptide standard (*** indicates BSA untagged tryptic peptides). Note that the potassium salt observed from the washed samples was due to the presence of potassium ions in the wash solution. 
a. $\mathrm{C}_{6} \mathrm{~F}_{13}$ Alkylated BSA Digest

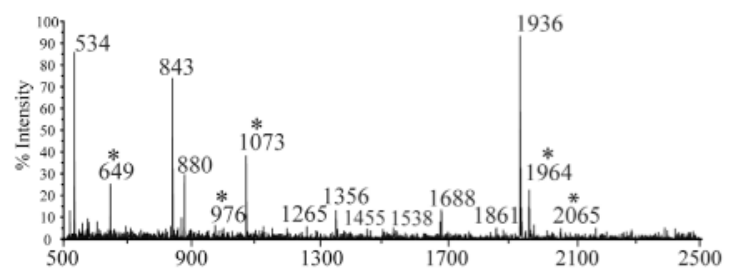

$\downarrow \begin{gathered}\text { washed with } \\ 50 \% \mathrm{MeOH} \text { in } \mathrm{H}_{2} \mathrm{O}\end{gathered}$

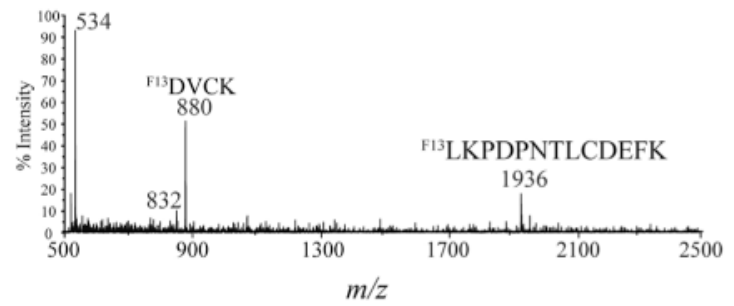

b. $\mathrm{C}_{6} \mathrm{~F}_{13}$ Alkylated $\alpha$-Casein Digest
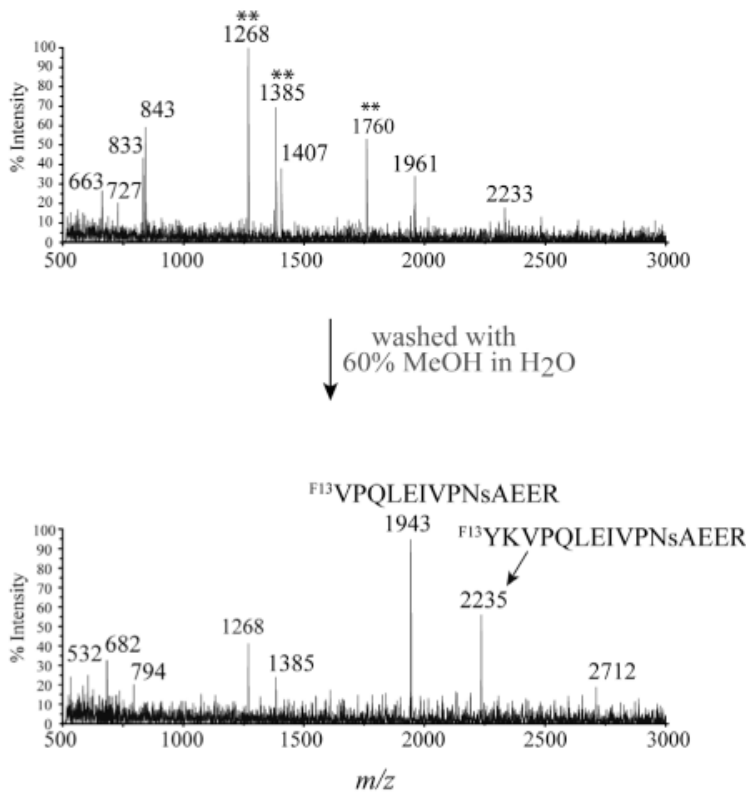

Figure 4.

DIOS-MS spectra before and after employing a surface washing step of the tryptic digests of a) 2 pmol BSA alkylated with a fluorous iodoacetamide, and b) 1 pmol $\alpha$-casein subjected to $\beta$-elimination followed by Michael addition with a fluorous thiol $(*$ and $* *$ indicate BSA and $\alpha$-casein untagged tryptic peptides, respectively). 
a. Fluorous Derivatization

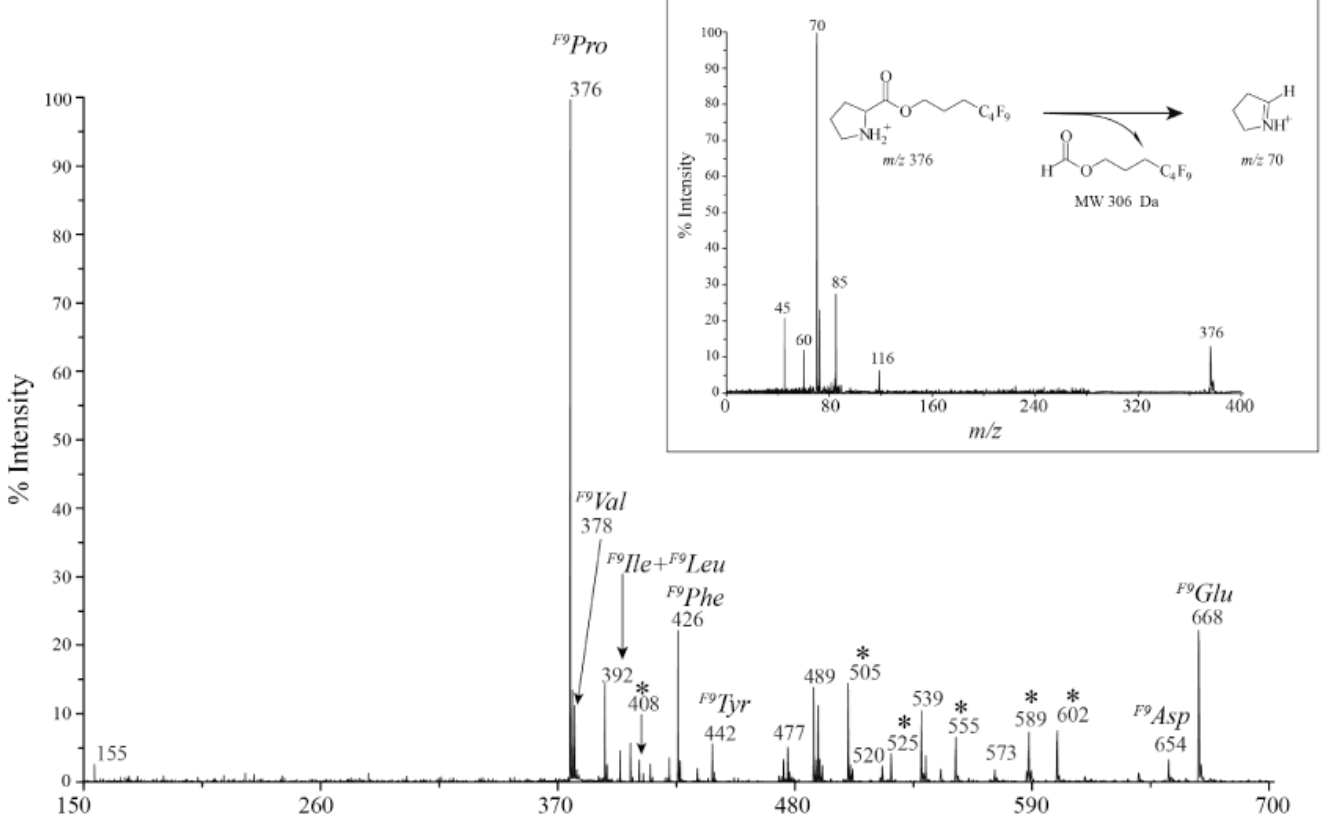

b. Butylation

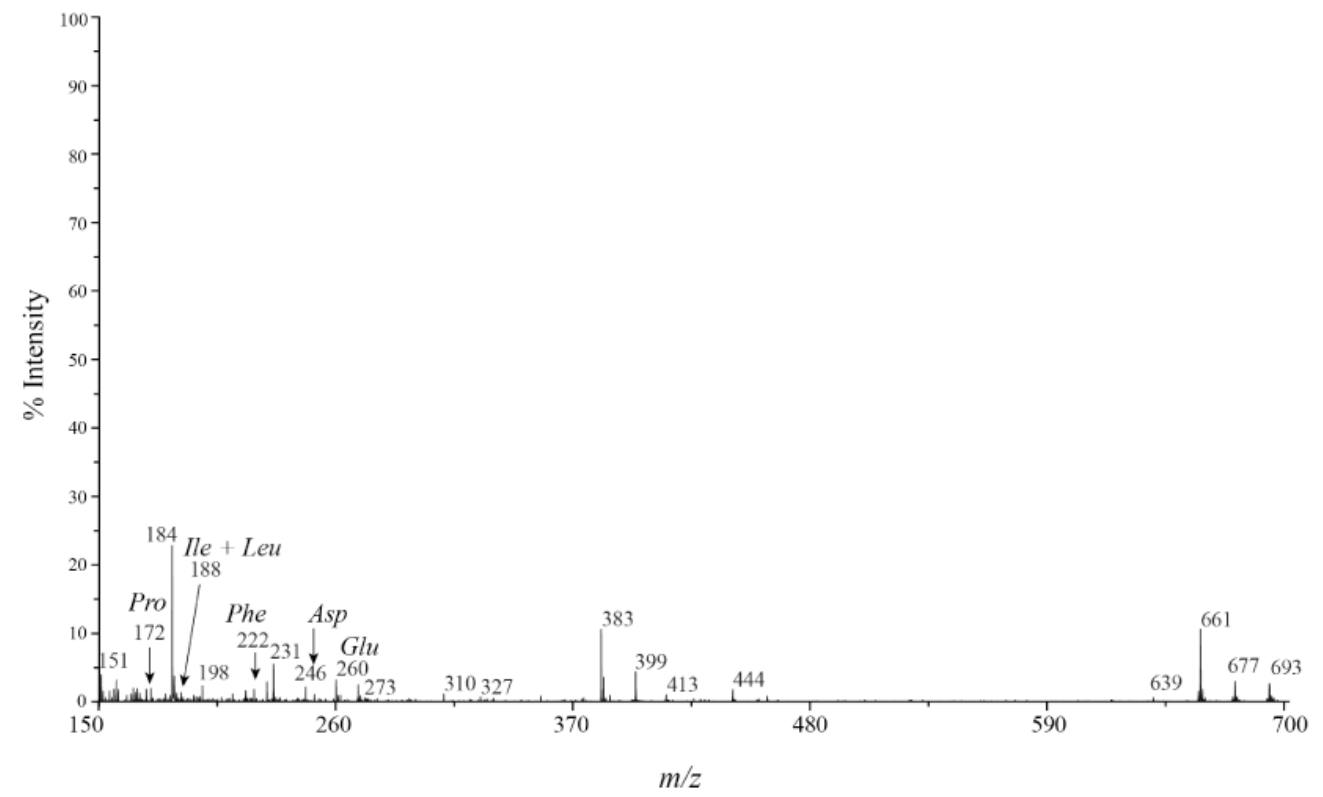

Figure 5.

DIOS-MS spectra of amino acids in human serum after a) fluorous or b) butyl esterification on a fluorous-silylated target. (peaks labeled with * in (a) indicate other metabolites containing a carboxylic acid functionality as indicated by the presence of a 306 Da neutral loss in the PSD and ESI-MS/MS spectra). 
Amino Acids

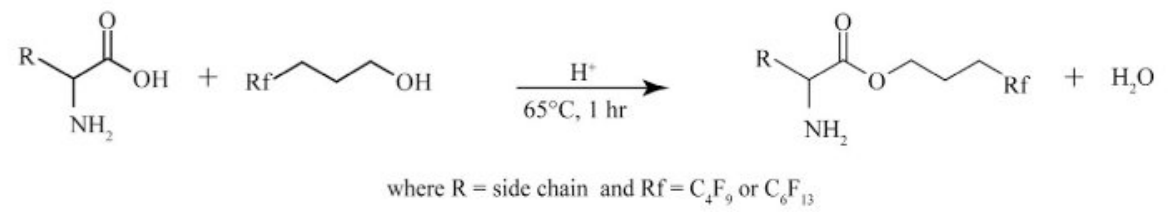

Carbohydrates

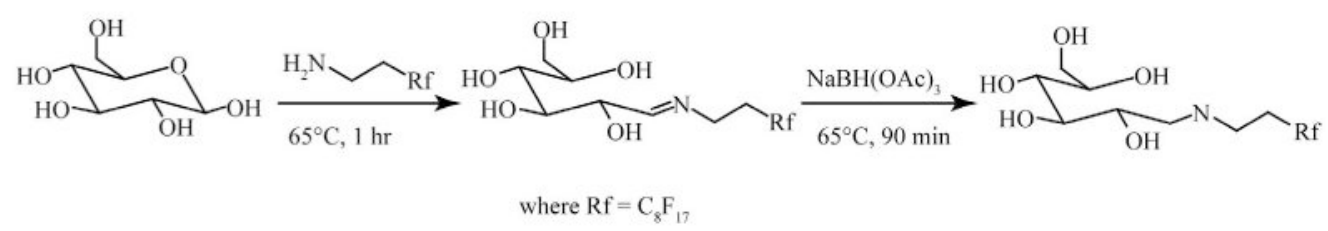

Scheme 1.

Fluorous derivatization of small molecules. 